\title{
Application of Quality Control and Statistical Tools to Demonstrate The Retrospective Process Validation
}

\author{
Abdul Wajid ${ }^{1}$ \\ ${ }^{I}$ (Hamdard Institute of Education and Social Sciences, Hamdard University Pakistan)
}

\begin{abstract}
The purpose of this effort is to provide an introduction and overview of the process validation of the production of pharmaceutical manufacturing process especially tablet with particular attention to the U.S. Food and Drug Administration requirements (FDA). Quality is always a prerequisite when looking at a product. Therefore, drugs must be manufactured to the highest quality standards. In the context of one of the types of process validation, retrospective validation are used for the facilities, processes and process controls in use that have not been subjected to a documented formal process validation (prospective, concurrent). The validation of these facilities, processes and process controls can use historical data to provide the necessary evidence that the process does what it is supposed to do provide the source of data for this study include, but are not limited to processing batch records and packing, process control charts, logs, maintenance records personnel changes, process capability studies, final data, including trend cards and storage stability validation results. Retrospective validation is the starting point for the non-regulated or Sami-regulated toward the compliance of cGMP and is less expensive exercise to evaluate and demonstrate the product quality. Application of statistical and quality control will give a strength, confidence and reliability to demonstrate the retrospective process validation
\end{abstract}

Keywords: Retrospective, Statistical Tool, Quality Control Tool, Validation, Process Validation

\section{Introduction}

Pharmaceutical Process Validation is the most important and recognized parameters of cGMP. The requirement of process validation appears of the quality system (QS) regulation. The goal of a quality system is to consistently produce products that are fit for their intended use. Process validation is a key element in assuring that these principles and goal are met [1].

We have considered here a historical evaluation approach to demonstrate the process consistency and reproducibility .i.e. Retrospective Validation, is Conducted for a product already being marked, and is based on extensive data accumulated over several lots and over time. Retrospective Validation may be used for older products which were not validated by the fabricator at the times that they were first marketed, and which are now to be validated to confirm to the requirements of division 2, Part C of the Regulation to be Food and Drugs Act. (USA) [2]

Retrospective Validation is only acceptable for well established detailed processes and will be Inappropriate where there have recent changes in the formulation of the products, operating procedures, equipment and facility [3].

Some of the essential elements for Retrospective Validation are

Batches manufactured for a defined period (Minimum of 10-30 last consecutive batches).

Number of lots released per year.

Batch size/strength/manufacturer/year/period.

Master manufacturing/packaging documents.

List of process deviations, corrective actions and changes to manufacturing documents.

Data for stability testing for several batches.

Trend analysis including those for quality related complaints [4]

To demonstrate the retrospective process validation of a drug product, Montiget $4 \mathrm{gm}$, a generic drug product, manufactured at Getz Pharma Pvt. Ltd Pakistan Karachi and is anti asthma which contains Montelukast as active pharmaceutical ingredient, applicable Quality Control tools (i.e. Check Sheet, Flow Chart, Cause \& Effect Diagram, Control Charts and Histogram) and Statistical tools (.i.e. Cpk, PpK, Normality Test and Descriptive statistics) will be applied, the use of capability indices such as $\mathrm{Cp}, \mathrm{Cpk}$, and "Sigma" values is widespread in industry[5]. Literature survey and review reveals that retrospective validation study is normally conducted as per approved protocol in the light latest international guidelines, use of quality control tools and effective statistical tool rarely observed in practice, this study will divinity give strength, reliability and confidence with the application of statistical and quality control tool to demonstrate the retrospective process validation of pharmaceutical drug product. 


\section{Strategy And Approach For Retrsospective Process Validation}

In order to conduct retrospective validation of Montiget 4mg Tablet, FDA, WHO and PIC/S guidelines were followed The purpose of this study is to establish the historical documented evidence which provides a high degree of assurance that the process of Montiget $4 \mathrm{mg}$ Tablet is consistently producing, the product meeting its pre-determined specifications and quality characteristics.

The purpose of this study is also to evaluate whether concurrent validation for this product is required or retrospective validation is sufficient to demonstrate process consistency and reproducibility. The scope of this study is applicable for the retrospective validation of last 20 batches of Montiget $4 \mathrm{mg}$ tablets, $163.9 \mathrm{~kg}$ batch size (500,000 tablets), manufactured at Getz Pharma Plant, Karachi Pakistan.

Fig-1, Flow Chart to depict the manufacturing of Montiget 4mg Tablet

Process Flow Diagram of The of Montiget $4 \mathrm{mg}$ Tablets

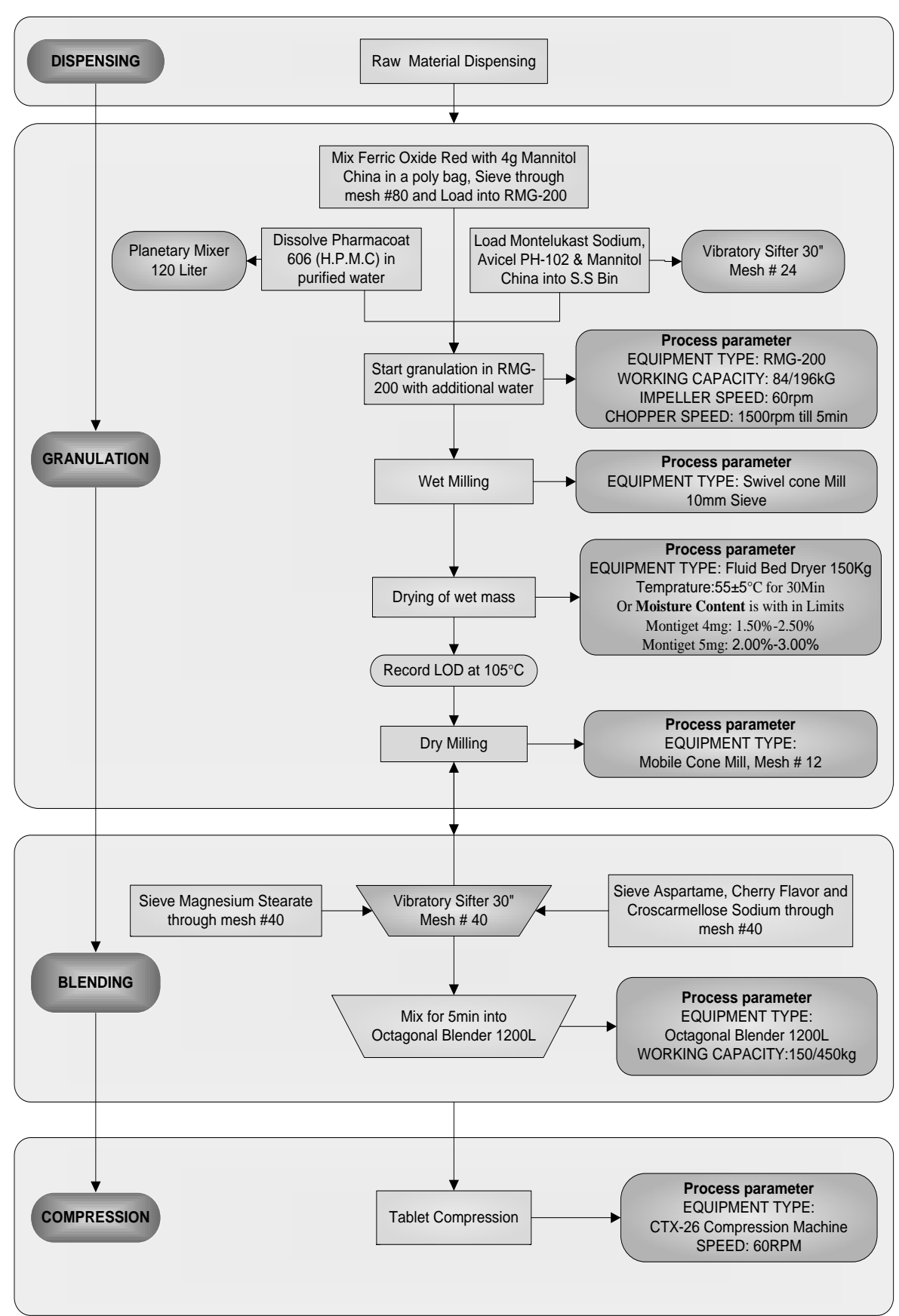


Fig-2, Cause \& Effect Diagram (Quality Control Tool, 1) to identify the correlation between the quality attributes and variable controls

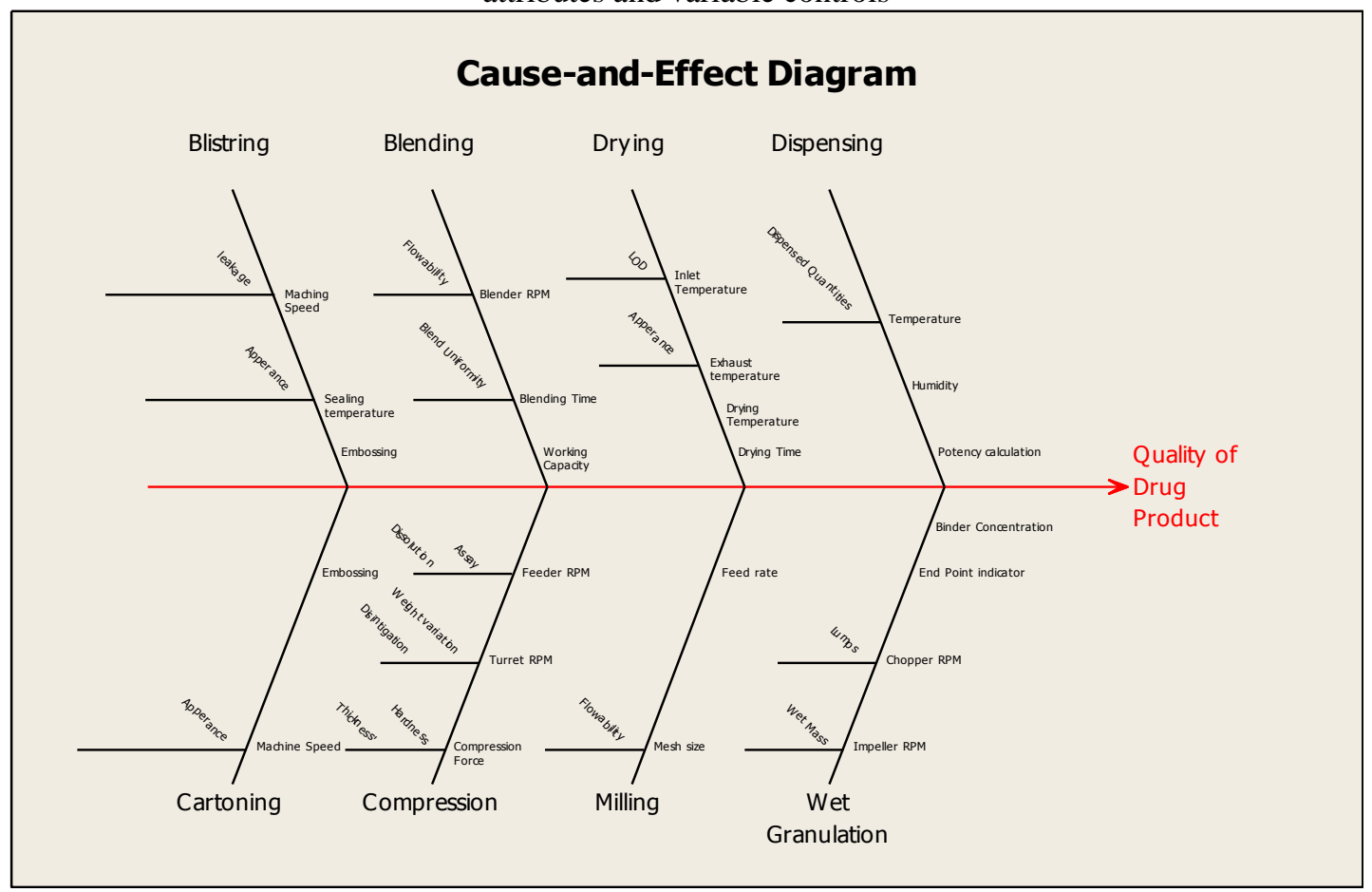

Fig-3, Use of Cause and Effect Diagram (Quality Control Tool, 2) for the demonstration of 6M of manufacturing process

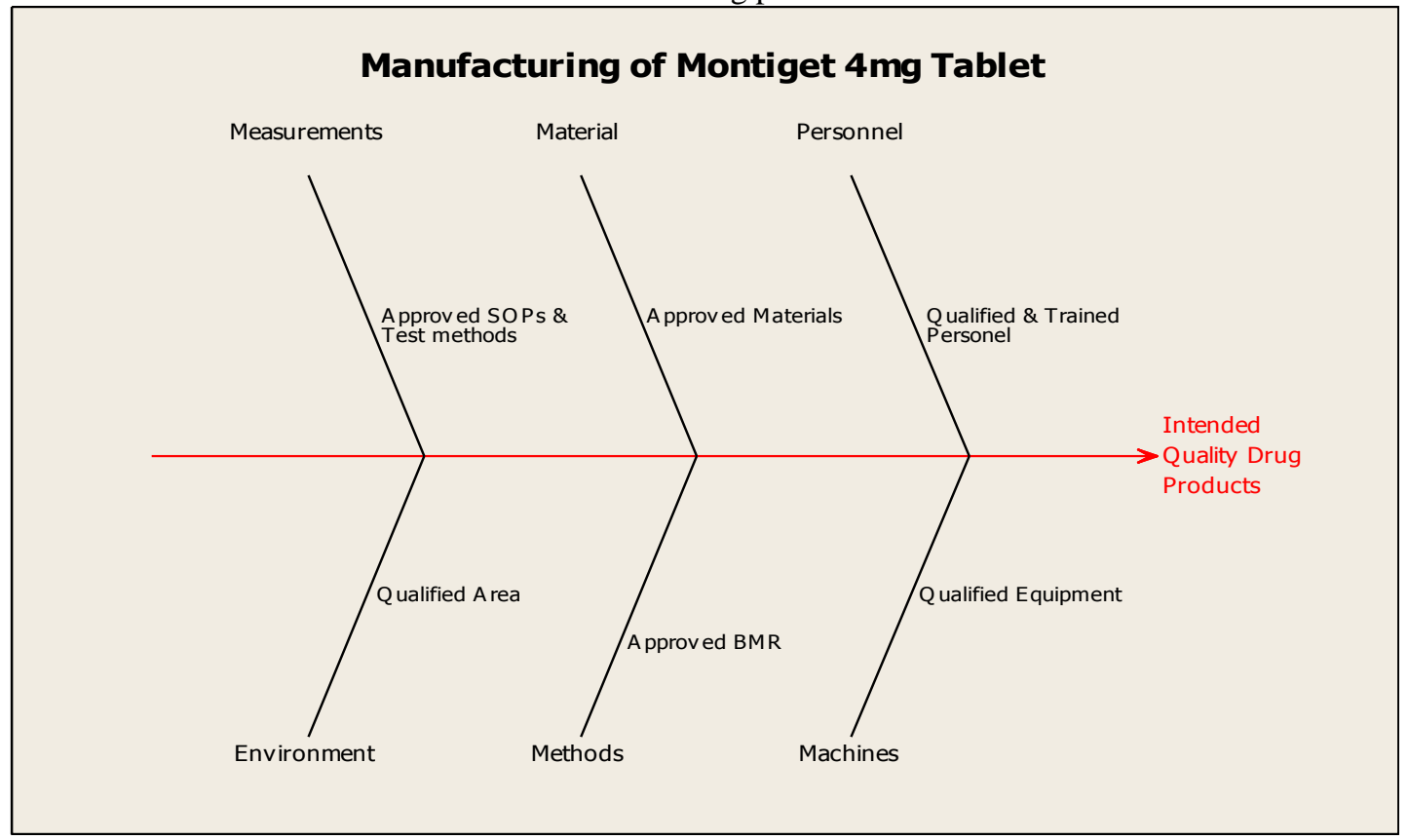


Table-1, Use of Check Sheet (Quality Control Tool, 3) for the evaluation documents used in manufacturing

\begin{tabular}{|c|c|c|c|}
\hline Title & Authorized & Approved & Adequate \\
\hline SOP for line clearance and IPC checks in dispensing area & $\sqrt{ }$ & $\sqrt{ }$ & $\sqrt{ }$ \\
\hline SOP for Line Clearance of Granulation Area & $\sqrt{ }$ & $\sqrt{ }$ & $\sqrt{ }$ \\
\hline SOP for Line Clearance of Compression Area & $\sqrt{ }$ & $\sqrt{ }$ & $\sqrt{ }$ \\
\hline SOP for Line Clearance of Blister Area & $\sqrt{ }$ & $\sqrt{ }$ & $\sqrt{ }$ \\
\hline SOP for Line Clearance of Packing Area & $\sqrt{ }$ & $\sqrt{ }$ & $\sqrt{ }$ \\
\hline SOP for Cleaning and Operation of RMG $200 \mathrm{~kg}$ & $\sqrt{ }$ & $\sqrt{ }$ & $\sqrt{ }$ \\
\hline SOP for Cleaning and Operation of Fluid Bed Dryer & $\sqrt{ }$ & $\sqrt{ }$ & $\sqrt{ }$ \\
\hline SOP for Cleaning and Operation of Fitz Mill I/II & $\sqrt{ }$ & $\sqrt{ }$ & $\sqrt{ }$ \\
\hline SOP for Cleaning and Operation Octa Blender & $\sqrt{ }$ & $\sqrt{ }$ & $\sqrt{ }$ \\
\hline SOP for Cleaning and Operation CTX Compression Machine & $\sqrt{ }$ & $\sqrt{ }$ & $\sqrt{ }$ \\
\hline SOP for the In-Process checks during Granulation, Blending & $\sqrt{ }$ & $\sqrt{ }$ & $\sqrt{ }$ \\
\hline SOP for the In-Process checks during Compression & $\sqrt{ }$ & $\sqrt{ }$ & $\sqrt{ }$ \\
\hline SOP for the In-Process checks during blistering & $\sqrt{ }$ & $\sqrt{ }$ & $\sqrt{ }$ \\
\hline SOP for the In-Process checks during Packing & $\sqrt{ }$ & $\sqrt{ }$ & $\sqrt{ }$ \\
\hline Test Method Specification & $\sqrt{ }$ & $\sqrt{ }$ & $\sqrt{ }$ \\
\hline Retrospective Validation Protocol & $\sqrt{ }$ & $\sqrt{ }$ & $\sqrt{ }$ \\
\hline Training record & $\sqrt{ }$ & $\sqrt{ }$ & $\sqrt{ }$ \\
\hline Equipment Qualification documents & $\sqrt{ }$ & $\sqrt{ }$ & $\sqrt{ }$ \\
\hline Area Qualification documents & $\sqrt{ }$ & $\sqrt{1}$ & $\sqrt{1}$ \\
\hline
\end{tabular}

\section{Manufacturing Process}

Montiget $4 \mathrm{mg}$ is manufactured with wet granulation process and core tablet

\subsection{Granulation}

All the critical process parameters of each step of last twenty (20) batches of Montiget $4 \mathrm{mg}$ were reviewed. For sieves 24, 40 and 80 mesh no. were used during the last 20 batches, integrity of mesh before and after sieving remained intact in all the reviewed batches and all the materials passed from the fitted mesh without any disruption. Granulation was carried out in RMG $200 \mathrm{Kg}$. The critical checks reviewed, all the Critical process parameters of granulation stage were found consistent throughout the reviewed batches of Montiget $4 \mathrm{mg}$ Tablet. Drying was carried out in FB Dryer $150 \mathrm{Kg}$ at $55^{\circ} \mathrm{C} \pm 5^{\circ} \mathrm{C}$ for 30 minutes or until moisture content is within limit $(1.50 \%-2.50 \%)$ All the Process control variables of drying stage were found satisfactory and \%LOD of both the lots was found consistent throughout the reviewed batches of Montiget $4 \mathrm{mg}$ Tablet .Blending was carried out in Octagonal Blender. The critical checks reviewed, all the batches were blended for 10 minutes and at 10 RPM

\subsection{Compression:}

Compression of Montiget 4mg Tablet was done on CTX-26 Compression Machine, at 298mg compressed weight (4\% internal and 5\% external limits), thickness4-4.8mm and hardness 3-15Kpa. Critical checks were reviewed, machine speed 60 RPM and Compression force were found $35 \mathrm{KN}$ throughout the reviewed batches. Assay, content uniformity and dissolution test results of last twenty batches were also reviewed, results were found consistent and within the specifications.

\section{Application of Quality Control and Statistical Tool}

Quality control and statistical tools were applied to interpret the data of quality attributes of critical process steps; tool will include descriptive statistics and six-pack analysis (Normality plot, capability histogram, and control chart and capability plot) with the use of Mintab16. 
Table-2

Below is data of blending stage yield, compression weight and compression yield of last twenty batches (Physical attributes)

\begin{tabular}{|c|c|c|c|c|}
\hline \multirow[t]{3}{*}{ S No. } & \multirow{3}{*}{$\begin{array}{c}\text { Batch } \\
\text { No. }\end{array}$} & $\%$ Blending Yield & Compressed Weight (mg) & \%Compression Yield \\
\hline & & \multicolumn{3}{|c|}{ Specifications } \\
\hline & & $(98-102) \%$ & $298.00 \mathrm{mg} \pm 5 \%$ & $(98-102) \%$ \\
\hline 1 & $063 \mathrm{~T} 16$ & 99.09 & 297.005 & 99.11 \\
\hline 2 & $064 \mathrm{~T} 16$ & 99.51 & 295.985 & 99.29 \\
\hline 3 & $065 \mathrm{~T} 16$ & 100.65 & 299.555 & 100.62 \\
\hline 4 & $066 \mathrm{~T} 16$ & 100.48 & 297.005 & 101.08 \\
\hline 5 & $067 \mathrm{~T} 16$ & 99.58 & 297.13 & 99.61 \\
\hline 6 & $068 \mathrm{~T} 16$ & 100.18 & 295.315 & 99.93 \\
\hline 7 & $069 \mathrm{~T} 16$ & 100.18 & 296.155 & 100.11 \\
\hline 8 & 070T16 & 98.95 & 302.695 & 98.66 \\
\hline 9 & $071 \mathrm{~T} 16$ & 100.28 & 294.48 & 99.45 \\
\hline 10 & $072 \mathrm{~T} 16$ & 99.96 & 294.895 & 99.87 \\
\hline 11 & $073 \mathrm{~T} 16$ & 100.04 & 298.445 & 99.7 \\
\hline 12 & $074 \mathrm{~T} 16$ & 99.74 & 299.24 & 99.93 \\
\hline 13 & $075 \mathrm{~T} 16$ & 100.61 & 298.03 & 99.28 \\
\hline 14 & 076T16 & 99.51 & 300.84 & 98.21 \\
\hline 15 & $077 \mathrm{~T} 16$ & 99.95 & 300.55 & 99.06 \\
\hline 16 & $078 \mathrm{~T} 16$ & 100.39 & 297.11 & 100.36 \\
\hline 17 & 079T16 & 99.54 & 300.44 & 99.13 \\
\hline 18 & 080T16 & 99.14 & 295.13 & 99.25 \\
\hline 19 & $081 \mathrm{~T} 16$ & 99.21 & 300.57 & 99.32 \\
\hline
\end{tabular}

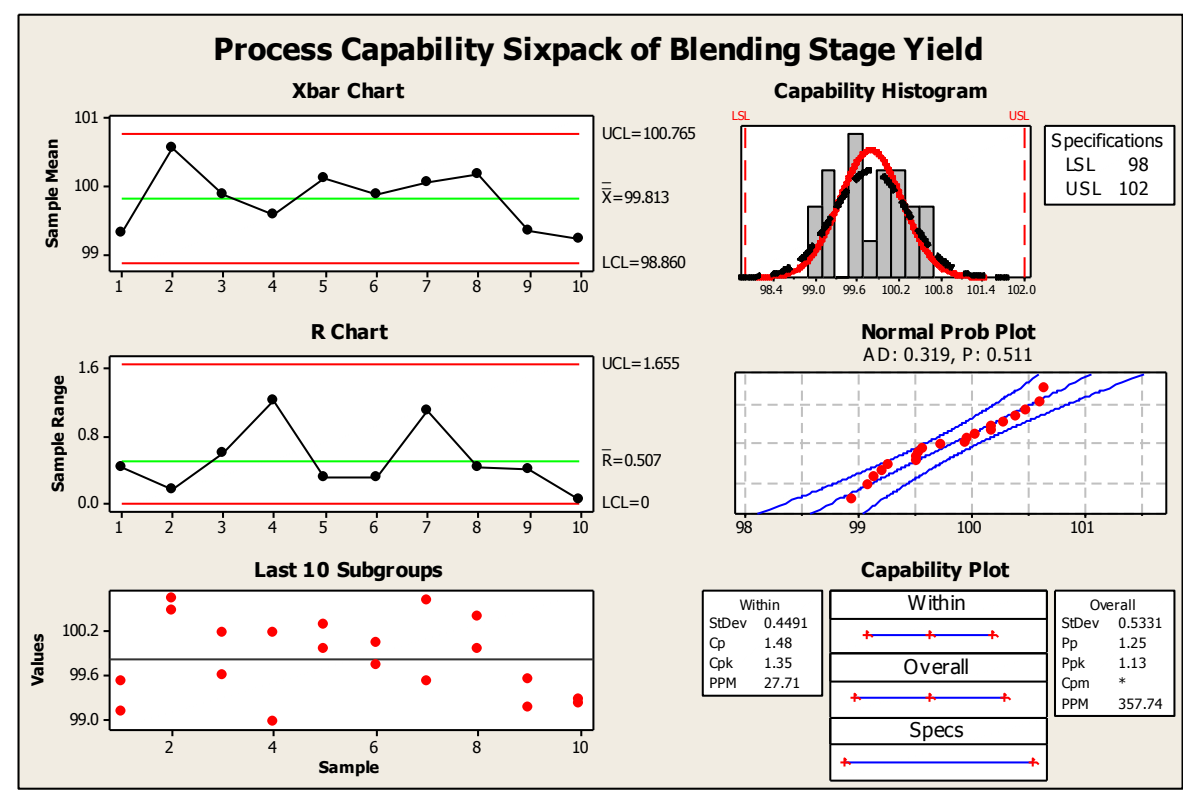

Interpretation: All the Critical process parameters of blending stage were found consistent throughout the reviewed batches of Montiget $4 \mathrm{mg}$ Tablet, six-pack analysis indicates that data is normally distributed, within the control specification and statistical control as the blending yield Cpk is 1.35 .i.e. it meets 4 sigma levels. 


\begin{tabular}{lr}
\hline Parameters & \multicolumn{2}{c}{ values } \\
\hline \multicolumn{1}{c}{ Descriptive Statistics (Blending Yield) } \\
\hline \\
Mean & 99.8125 \\
Standard Error & 0.119214259 \\
Median & 99.845 \\
Mode & 99.51 \\
Standard Deviation & 0.533142373 \\
Sample Variance & 0.284240789 \\
Kurtosis & 1.7 \\
Skewness & 98.95 \\
Range & 100.65 \\
Minimum & 1996.25 \\
Maximum & 20 \\
Sum & 0.001873301 \\
Count & \\
Confidence Level(95.0\%) & 0.249518311 \\
\hline
\end{tabular}

\begin{tabular}{|c|c|}
\hline Parameters & Values \\
\hline \multicolumn{2}{|c|}{ Descriptive Statistics (Compression Yield) } \\
\hline Mean & 99.528 \\
\hline Standard Error & 0.156238 \\
\hline Median & 99.385 \\
\hline Mode & 99.93 \\
\hline Standard Deviation & 0.698718 \\
\hline Sample Variance & 0.488206 \\
\hline Kurtosis & 0.20767 \\
\hline Skewness & 0.329506 \\
\hline Range & 2.87 \\
\hline Minimum & 98.21 \\
\hline Maximum & 101.08 \\
\hline Sum & 1990.56 \\
\hline Count & 20 \\
\hline Confidence Level $(95.0 \%)$ & 0.32701 \\
\hline
\end{tabular}

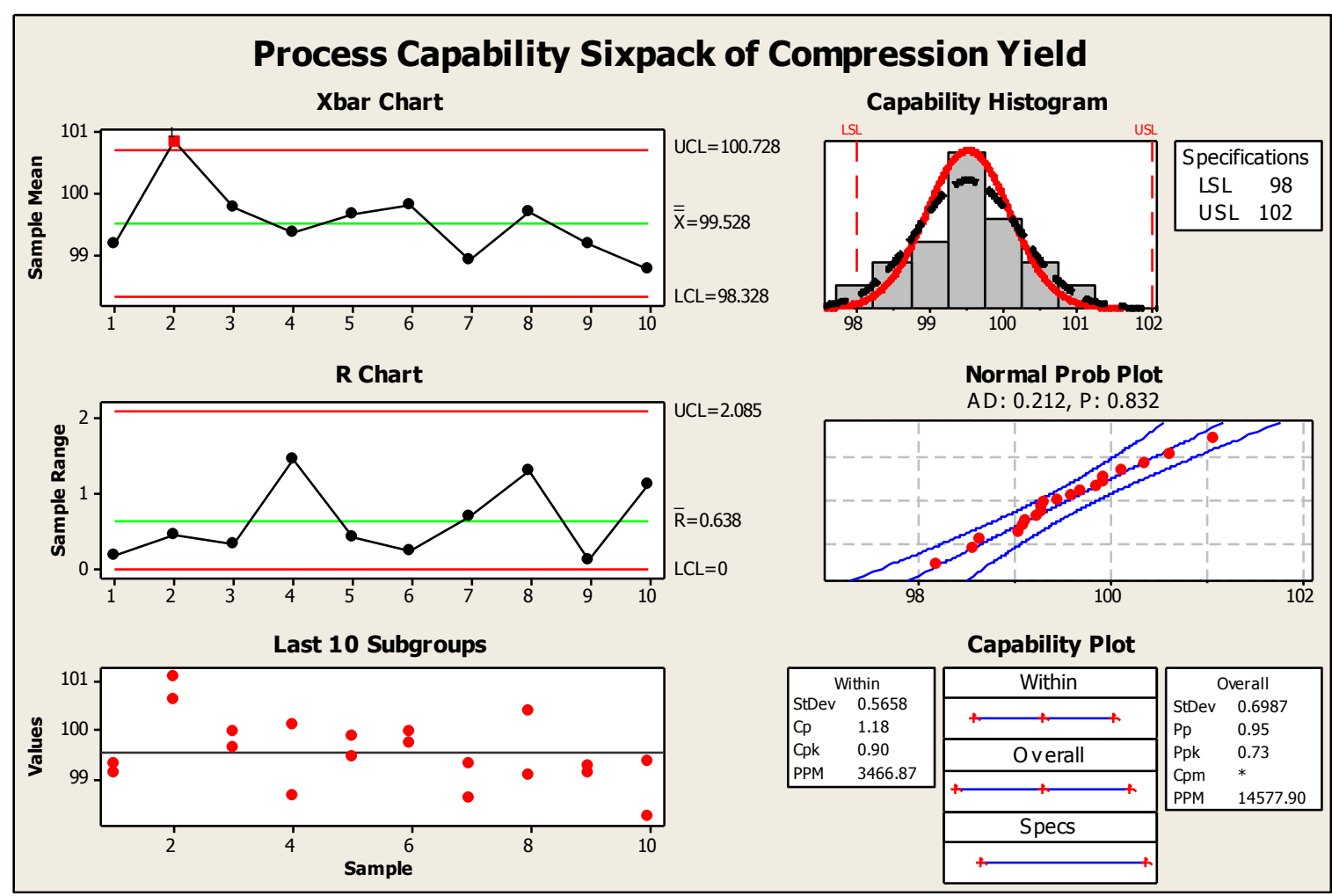

Interpretation: All the Critical process parameters of compression stage were thoroughly reviewed including the physical parameters and found consistent throughout the reviewed batches of Montiget 4mg Tablet, yield sixpack analysis indicates that data is normally distributed, within the control specification and statistical control however as $\mathrm{Cpk}$ is 0.9 (2.75 sigma) .i.e. it does not meet meets 4 sigma levels. 


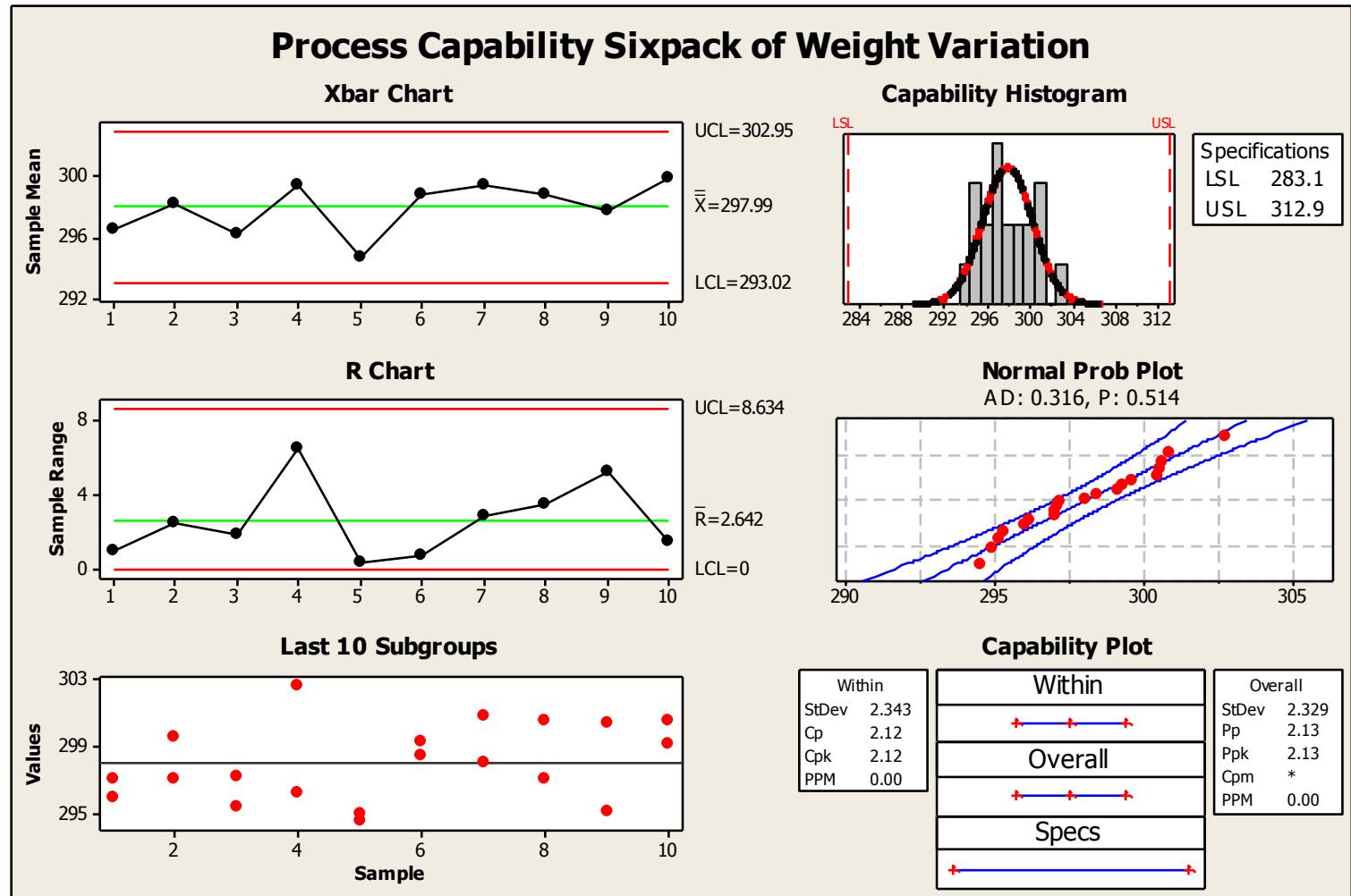

Interpretation: Sixpack analysis of most critical parametrs .i.e compression weight indicate that data is normally distributed, statistically controled and within specification thougout the reviewed batches. Capability analysis (Cpk 2.12) indicates that process meet six sigma level.

Table -3, Assay, Contents uniformity and Dissolution data of Montiget 4mg Tablet (chemical attributes)

\begin{tabular}{|c|c|c|c|c|}
\hline \multirow{2}{*}{ S No. } & \multirow{2}{*}{ Batch No. } & $\begin{array}{c}\text { Assay of } \\
\text { Montelukast }\end{array}$ & $\begin{array}{c}\text { Uniformity of Dosage Unit } \\
\text { by CU }\end{array}$ & $\begin{array}{c}\text { Dissolution of } \\
\text { Montelukast }\end{array}$ \\
\cline { 3 - 5 } & & \multicolumn{2}{|c|}{ Specifications } & NLT 70\% \\
\cline { 3 - 5 } & & $\mathbf{9 0 - 1 1 0 \%}$ & $\mathbf{8 5 - 1 1 5 \%}$ & 96.468 \\
\hline 1 & $063 \mathrm{~T} 16$ & 101.643 & 102.061 & 99.820 \\
\hline 2 & $064 \mathrm{~T} 16$ & 106.972 & 100.475 & 99.856 \\
\hline 3 & $065 \mathrm{~T} 16$ & 104.978 & 106.443 & 96.141 \\
\hline 4 & $066 \mathrm{~T} 16$ & 104.885 & 107.527 & 101.173 \\
\hline 5 & $067 \mathrm{~T} 16$ & 103.111 & 103.193 & 100.338 \\
\hline 6 & $068 \mathrm{~T} 16$ & 100.490 & 100.349 & 99.871 \\
\hline 7 & $069 \mathrm{~T} 16$ & 98.273 & 101.786 & 98.099 \\
\hline 8 & $070 \mathrm{~T} 16$ & 100.538 & 97.371 & 96.599 \\
\hline 9 & $071 \mathrm{~T} 16$ & 104.087 & 106.324 & 105.326 \\
\hline 10 & $072 \mathrm{~T} 16$ & 101.136 & 101.369 & 89.106 \\
\hline 11 & $073 \mathrm{~T} 16$ & 103.510 & 99.463 & 89.489 \\
\hline 12 & $074 \mathrm{~T} 16$ & 100.601 & 101.120 & 96.990 \\
\hline 13 & $075 \mathrm{~T} 16$ & 101.446 & 101.471 & 94.400 \\
\hline 14 & $076 \mathrm{~T} 16$ & 104.340 & 104.360 & 99.600 \\
\hline 15 & $077 \mathrm{~T} 16$ & 104.160 & 101.000 & 101.960 \\
\hline 16 & $078 \mathrm{~T} 16$ & 100.880 & 100.410 & 105.410 \\
\hline 17 & $079 \mathrm{~T} 16$ & 104.760 & 102.340 & 104.420 \\
\hline 18 & $080 \mathrm{~T} 16$ & 102.190 & 101.750 & 95.170 \\
\hline 19 & $081 \mathrm{~T} 16$ & 101.140 & 98.030 & \\
\hline 20 & $082 \mathrm{~T} 16$ & 100.690 & 102.060 & \\
\hline
\end{tabular}




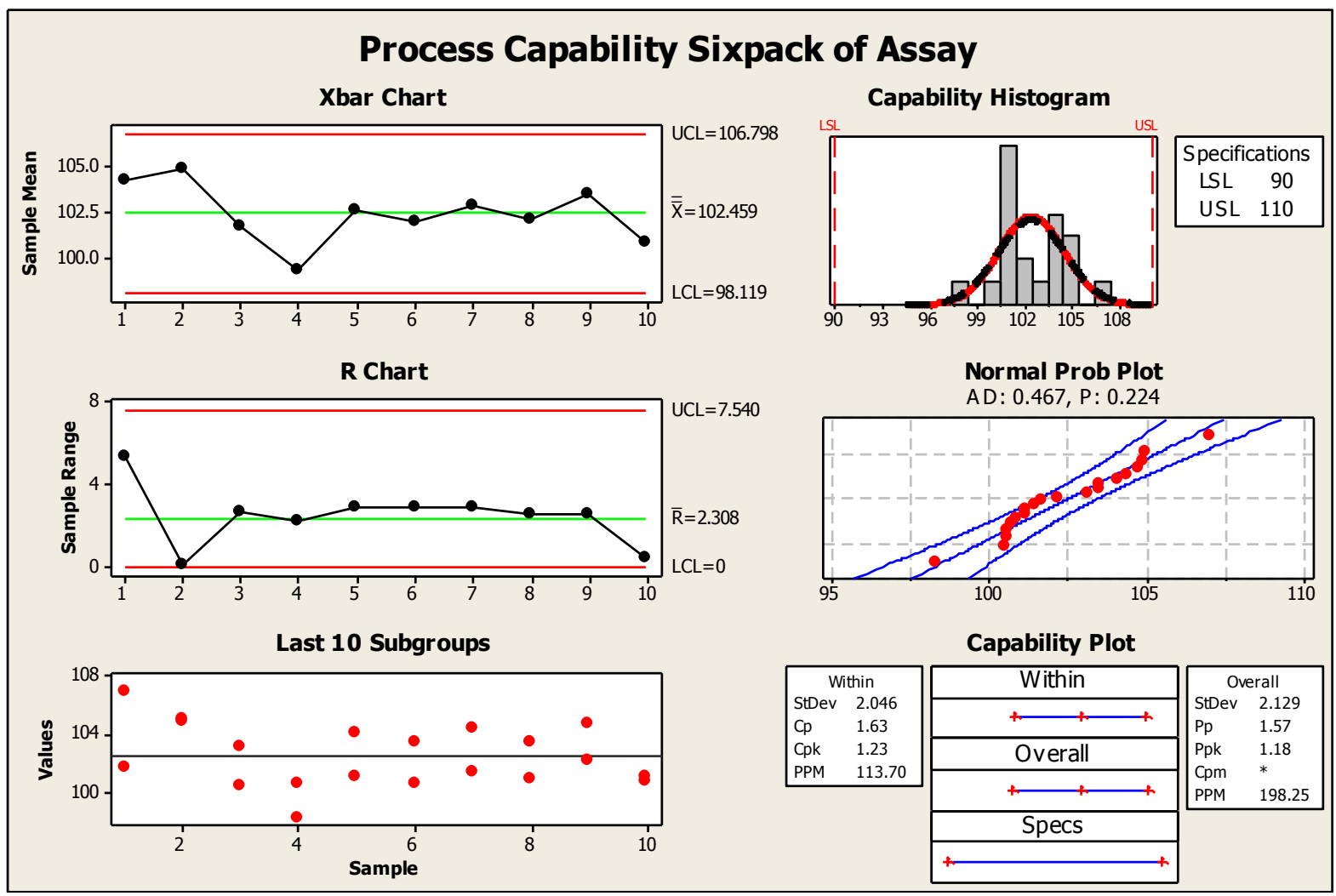

Interpretation: All the twenty batches assay results are well within the specifications and descriptive statistics and six pack analyses indicates, data is normally distributed, the process is statistically control as Cpk is 1.23 , means it meets 3.75 sigma level, does not meet 4sigma.

\begin{tabular}{cc}
\hline Parameters & Values \\
\hline Descriptive Statistics (Assay) & \\
\hline
\end{tabular}

\begin{tabular}{ll} 
Mean & 102.4585 \\
Standard Error & 0.476041 \\
Median & 101.9165 \\
Mode & $\# N / A$ \\
Standard Deviation & 2.128918 \\
Sample Variance & 4.532293 \\
Kurtosis & -0.33492 \\
Skewness & 0.229434 \\
Range & 8.699 \\
Minimum & 98.273 \\
Maximum & 106.972 \\
Sum & 2049.17 \\
Count & 20 \\
Confidence Level (95.0\%) & 0.996364 \\
\hline
\end{tabular}

\begin{tabular}{c}
\hline Parameters \\
\hline Descriptive Statistics (Dissolution) \\
\hline
\end{tabular}

\begin{tabular}{ll} 
Mean & 98.54835 \\
Standard Error & 0.99214 \\
Median & 99.71 \\
Mode & $\# N / A$ \\
Standard Deviation & 4.436984 \\
Sample Variance & 19.68683 \\
Kurtosis & 0.357882 \\
Skewness & -0.54738 \\
Range & 16.304 \\
Minimum & 89.106 \\
Maximum & 105.41 \\
Sum & 1970.967 \\
Count & 20 \\
Confidence Level(95.0\%) & 2.076573 \\
\hline
\end{tabular}




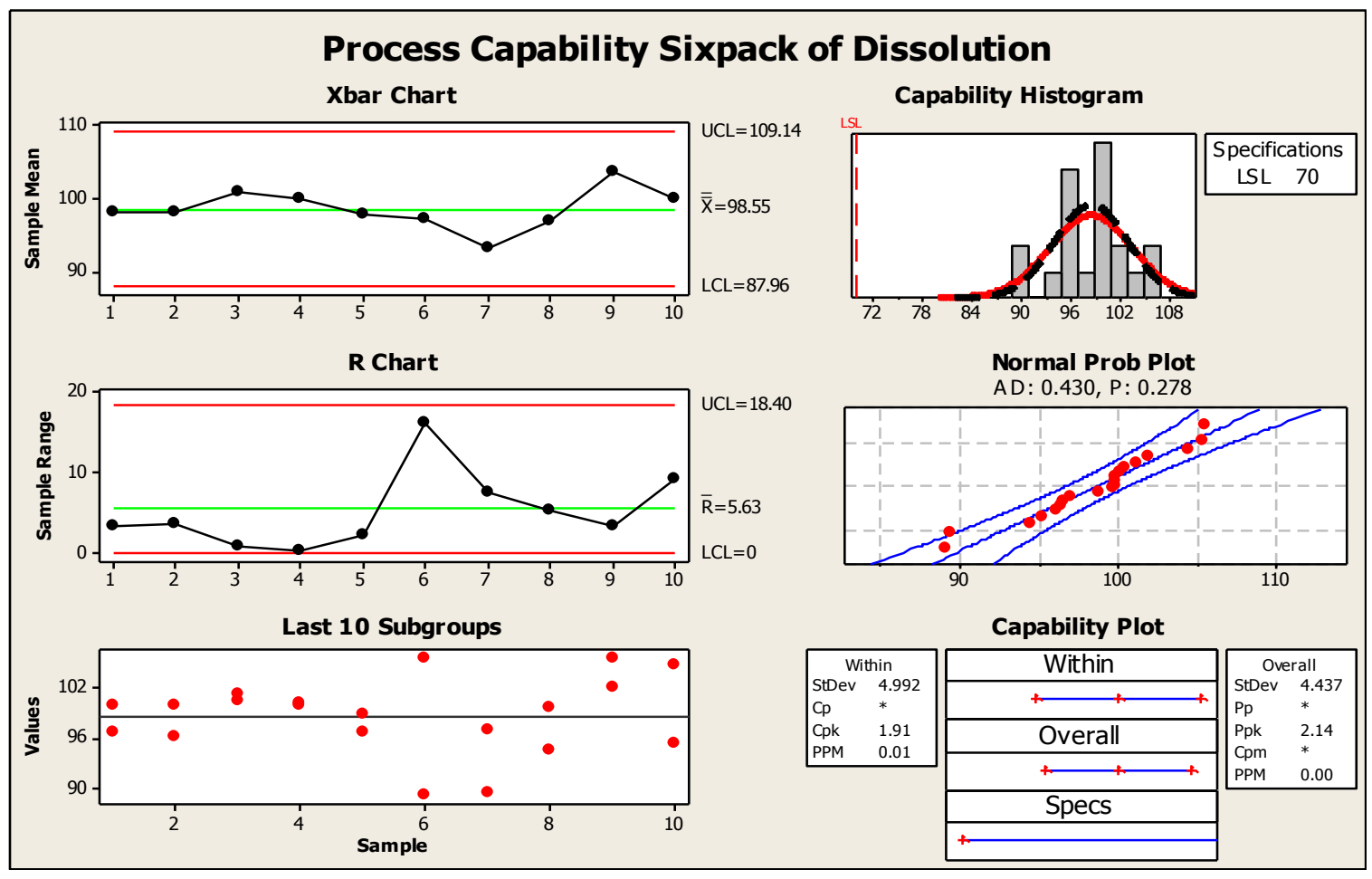

Interpretation: All the twenty batches dissolution results are well within the specifications and descriptive statistics and six pack analyses indicates, data is normally distributed, the process is statistically control as Cpk is 1.91 , means it meets 5.75 sigma level.

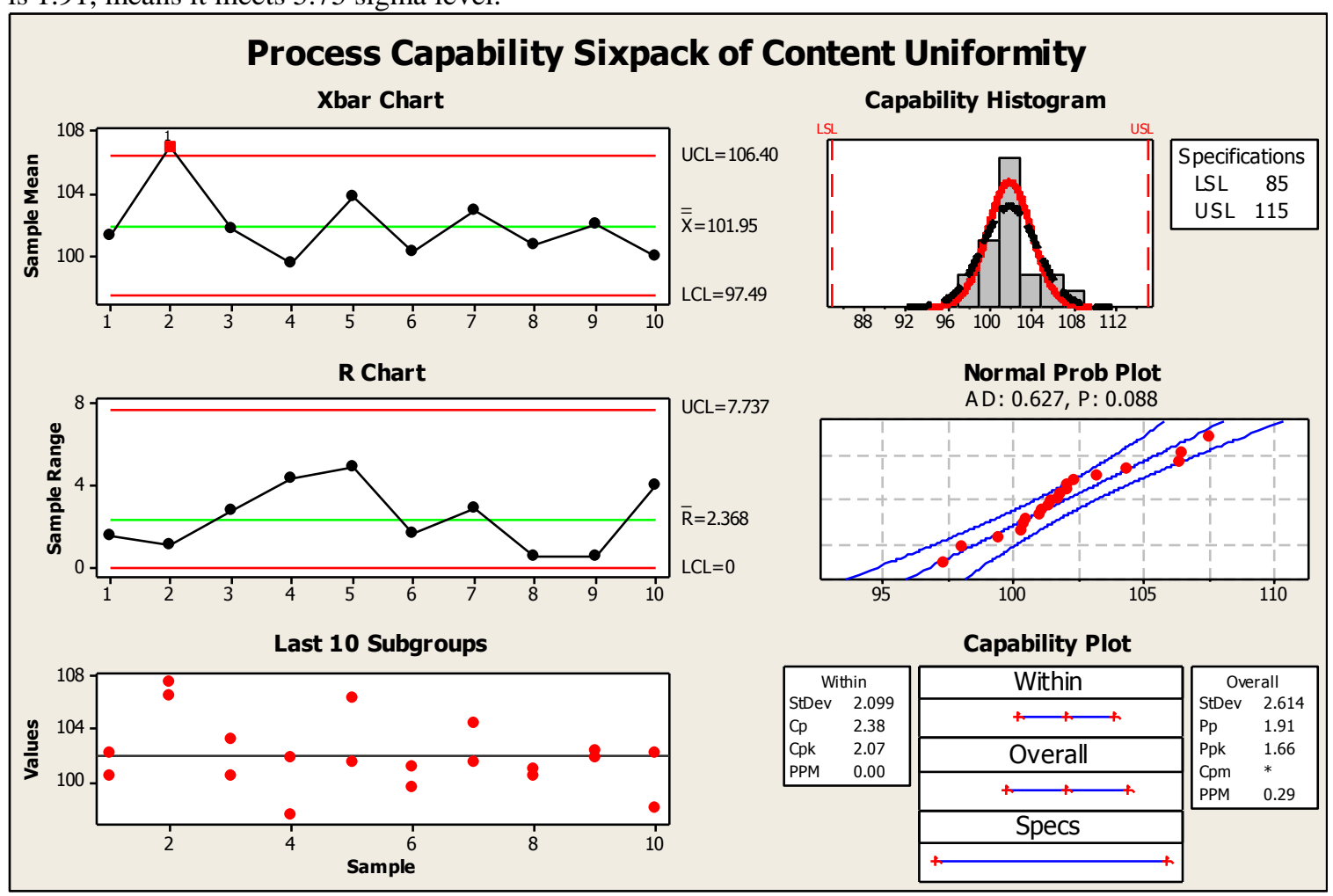

Interpretation: All the twenty batches dissolution results are well within the specifications and descriptive statistics and six pack analyses indicates, data is normally distributed, the process is statistically control as Cpk is 2.07 , means it meets 6 sigma level. 


\begin{tabular}{ll}
\hline Parameters & Values \\
\hline \multicolumn{1}{c}{ Descriptive Statistics (Content Uniformity ) } \\
\hline & \\
Mean & 101.9451 \\
Standard Error & 0.58446 \\
Median & 101.6105 \\
Mode & $\#$ N/A \\
Standard Deviation & 2.613785 \\
Sample Variance & 6.831873 \\
Kurtosis & 0.350245 \\
Skewness & 0.594036 \\
Range & 10.156 \\
Minimum & 97.371 \\
Maximum & 107.527 \\
Sum & 2038.902 \\
Count & 20 \\
Confidence Level $(95.0 \%)$ & 1.223289 \\
\hline
\end{tabular}

\section{Overall Data Evaluation and Illustration,}

\begin{tabular}{|c|c|c|c|c|c|c|c|c|c|}
\hline & \multicolumn{9}{|c|}{ Table-4 } \\
\hline S.No & Step & Parameters & Cp & Cpk & $\mathbf{P p}$ & PpK & Kurtosis & Skewness & $\begin{array}{l}\text { Standard } \\
\text { Deviation }\end{array}$ \\
\hline 1 & Blending & Yield & 1.48 & 1.35 & 1.25 & 1.13 & 1.66 & -1.36 & 0.118 \\
\hline 2 & \multirow{5}{*}{ Compression } & Weight Variation & 2.12 & 2.12 & 2.15 & 2.15 & -0.88 & 0.25 & 2.32 \\
\hline 3 & & Assay & 1.83 & 1.23 & 1.57 & 1.18 & -0.33 & 0.22 & 2.12 \\
\hline 4 & & $\begin{array}{l}\text { Content } \\
\text { Uniformity }\end{array}$ & 2.38 & 2.07 & 1.91 & 1.66 & 0.35 & 0.54 & 2.61 \\
\hline 5 & & Dissolution & - & 1.91 & - & 2.14 & 0.35 & -0.54 & 4.43 \\
\hline 6 & & Yield & 0.9 & 1.18 & 0.95 & 0.75 & 0.207 & 0.32 & 0.66 \\
\hline
\end{tabular}

\section{Findings And Recommendations}

Overall data indicate that Montiget $4 \mathrm{mg}$ tablet manufacturing process approach to 4 sigma level, consistently zmeeting its intended pre determined specifications and quality attributes, however there is slightly improvement is required to further enhance the compliance and productivity, assay and yield at compression stage, these two process need to investigate and find out the root cause why these two process does not meet the 4 sigma level, however over all drug quality and productivity meet the USP and Getz Pharma specification.

\section{Conclusion}

Based on the data studied and reviewed, the product "Montiget 4mg Tablet" batch no 063T16-0824T16 (last 20 batches) were manufactured as per BMR and each batch from dispensing to final packing stage were reviewed and evaluated using statistical and quality control tools

No change or deviation in any process stage and batch were observed and product significantly comply the retrospective process validation definition and concept

All the 20 batches of Montiget $4 \mathrm{mg}$ Tablet were consistent in all prospects i.e. process, formulation, equipments and quality attributes. The data of these 20 batches are adequate and sufficient to declare the process to be robust, consistent and reproducible based on retrospective process validation and approaches 4 sigma levels. However, if any change is brought in the product i.e. change in process, equipment or formulation or any change which have a direct or indirect impact on the quality of product then concurrent validation will be planned on 03 consecutive batches.

Hence, it is concluded that the product, "Montiget $4 \mathrm{mg}$ Tablet" based on historical data reviewed and statistical and quality control tools interpretations, is consistently leading to its predetermined specification and quality attributes.

Based on this over all study it is conclude that retrospective process validation may be starting point for the development counties with the use of quality control and statistical tool to demonstrate the quality of drug product based on historical data in accordance with FDA, WHO and PIC/S relevant guidelines, is the valuable 
tool to identify the area of improvement in the process and application of these tool will also be beneficial for the annual product review program as part of GMP.

\section{Reference}

[1] Guidance for Industry: Process Validation: General Principles and Practices. U.S. Department of Health and Human Services, Food and Drug Administration, Centre for Drug Evaluation and Research (CDER), Centre for Biologics Evaluation and Research (CBER), Centre for Veterinary Medicine (CVM), January 2011.

[2] Md. Shoaib Alam, Pharmaceutical Process Validation, an Overview, Journal of Advanced Pharmacy Education \& Research Oct-Dec 2012 Vol 2 Issue 4

[3] PIC/S Guide to good manufacturing practice for medicinal product, PE 009-10(annexes) Annex 15, 1 Jan 2013

[4] Md. Shoaib Alam, Pharmaceutical Process Validation, an Overview, Journal of Advanced Pharmacy Education \& Research Oct-Dec 2012 Vol 2 Issue 4

[5] Keith M. Bower, M.S Process Capability Analysis Using MINITAB 